\title{
The usefulness of diffusion-weighted MRI in the differentiation between focal uterine endometrial soft tissue lesions
}

\author{
Tarek Mohamed M. Mansour ${ }^{1 *}$ (D), Yasser Abd Al-aal Ahmed ${ }^{1}$ and Ghada Abd El-Razik Ahmed²
}

\begin{abstract}
Background: Several endometrial conditions may be challenging for radiologists due to the overlap of imaging features and variable endometrial pathologies. MRI with DWI is the most commonly used imaging technique for the diagnosis and characterization of endometrial focal lesions.

Results: The 50 studied lesions were classified according to their histopathological results into the benign group (28 lesions, 56\%) and the malignant group (22 lesions, 44\%). Conventional MRI could correctly diagnose 39 of the 50 lesions (22/28 benign and $17 / 22$ malignant lesions), achieving a sensitivity of $77.27 \%$, specificity of $78.56 \%$, accuracy of 78\%, predictive positive value (PPV) of 73.91\%, and negative positive value (NPV) of $81.48 \%$. By combining DWI and apparent diffusion coefficient (ADC) value mapping at a high $b$ value $(b=1000)$ in MRI, we could correctly diagnose 47 of the 50 lesions (26/28 benign and 21/22 malignant lesions), with increased sensitivity (95.45\%), specificity (92.86\%), accuracy (94\%), PPV (91.3\%), and NPV (96\%).

Conclusion: Combining DWI with ADC mapping at a high $b$ value in pelvic MRI examination is valuable in differentiating endometrial focal lesions with increased diagnostic sensitivity, specificity, and accuracy.

Aim of the work: This study aimed to evaluate the role of DWI in the diagnosis and differential diagnosis of benign and malignant focal endometrial masses.
\end{abstract}

Keywords: DWMRI, Endometrium, Endometrial mass lesions

\section{Background}

Uterine malignancies are considered the most common gynecological cancers. Endometrial and cervical carcinomas as well as uterine sarcomas are among the top list [1]. Most endometrial conditions show overlap in terms of imaging features with normal menstrual endometrial phases and variable endometrial pathologies, such as endometrial hyperplasia, polyps, submucosal fibroid, and endometrial carcinoma [2, 3]. Endometrial carcinoma is considered the most common female genital malignancy and the fourth most common type of female cancer [4]. MRI is more specific and accurate than ultrasound (US) in characterizing the endometrial masses. It is also more sensitive in identifying the anatomical origin, shape,

\footnotetext{
* Correspondence: Drtarekrad@gmail.com

${ }^{1}$ Radio-diagnosis Department, Faculty of Medicine, Al-Azhar University, Assiut, Egypt

Full list of author information is available at the end of the article
}

composition, and enhancement pattern of these masses; narrowing the differential diagnosis; and making a definitive diagnosis [5, 6]. Diffusion-weighted (DW) MRI depends on the random motion of water molecules within different tissues [7]. The DWI provides excellent tissue contrast, and when associated with apparent diffusion coefficient (ADC) mapping, DWI can be used to assess metastatic lesions, peritoneal deposits, tumor recurrence, and treatment response $[8,9]$.

DWI is a T2-weighted sequence in which we use two equal and opposite motion-probing gradients before and after the $180^{\circ}$ refocusing pulse. The freely moving water molecules when exposed to the first gradient pulse, they acquire phase shift information and when they exposed to the second gradient but as they are moving when they are exposed to the second gradient they are not in the same location and thus are not exposed to precisely the same gradient. Hence no signal is produced at the time of 
acquisition (free diffusion), however, static water molecules (diffusion restricted) regain signal, as no significant phase shift has occurred by the time of the second gradient and the signal loss from the first gradient is regained by the second opposite gradient (restricted diffusion) $[9,10]$.

The ADC value is a quantitative measure of the diffusion in each pixel, and it appears as an image which can use in visual assessment of the diffusion value. The number of $b$ values taken varies; generally, the more the $b$ values, the more accurate is the calculated ADC value. In our study, we take three $b$ values: 0,500 , and 1000 .

The advanced diffusion imaging techniques such as diffusion tensor imaging, diffusion spectral imaging, and whole-body diffusion-weighted imaging with background suppression (DWIBS) have a role in the assessment of pelvic floor muscles and uterine musculature before fertility-preserving surgery as well as used to detect thoracic and abdominal metastatic spread. These techniques can potentially map the nerve fiber preoperatively, which can guide surgeons during surgery and reduce postoperative complications [10].

Functional imaging in the form of diffusion-weighted imaging (DWI) has been recently found to be very useful in assessing various tumors. Its ability to identify changes in the molecular level has dramatically changed the diagnostic approach of radiologists which based on the morphological criteria. It can improve the diagnostic accuracy of conventional magnetic resonance imaging and tumor response to treatment regimens and detect tumor recurrence with better spatial resolution.

Our study assesses the role of MRI diffusion on endometrial lesions only not on all uterine lesions and does not include the myometrium or cervical lesions to be more specific. Also, our study combined the result with a histopathological examination to be more accurate and compare the results with other studies.

\section{Methods}

This study included 50 patients, who complained of vaginal bleeding and showed on US examination endometrial thickening and focal lesions of the endometrium with different echo pattern. The age of patients was between 25 and 87 years, with an average of 49.6 years. Ethics committee approval was obtained in addition to written informed consent from all included patients.

\section{Inclusion criteria}

All the patients who clinically complained of vaginal bleeding with US findings of suspicious uterine focal lesion were included.

\section{Exclusion criteria}

Exclusion criteria included all patients with absolute contraindication to MRI (patients having cardiac pacemakers, prosthetic heart valves, cochlear implants, or any metallic implants) and all patients having a history of claustrophobia or noisy/non-diagnostic MRI/ DWI examinations due to motion artifacts.

\section{MRI examination}

MRI was performed on a 1.5-T MR imaging unit (Philips Achieva). All patients examined in a supine position using a pelvic phased-array coil and nothing per oral for $3 \mathrm{~h}$. IV injection of an antispasmodic drug $(10 \mathrm{mg}$ of Visceralgine) was given immediately before MR imaging to reduce bowel peristalsis.

\section{MR imaging protocol}

- Localizer images in axial, coronal, and sagittal planes

- Fast spin echo (FSE) T1- and T2-weighted images (TR $497 \mathrm{~ms}$ and TE $12 \mathrm{~ms}$, and TR $3.3 \mathrm{~s}$ and TE 90 $\mathrm{ms}$ ), matrix $320 \times 512$, slice thickness $4-5 \mathrm{~mm}$ with an inter-slice gap of 1-2 mm, FOV $250 \mathrm{~mm}$, and a flip angle of 90 in axial, coronal, and sagittal plane

- DW-MRI using a single-shot spin echo planar sequence with free breathing; the following parameters were used: TR $2.8 \mathrm{~s}$, TE 72, matrix $512 \times$ 512, slice thickness $4 \mathrm{~mm}$ with an inter-slice gap of 1 $\mathrm{mm}$, and FOV $300 \mathrm{~mm}$ were acquired on axial plane. The diffusion sensitizing gradients were applied using a $b$ factor of 0,500 , and $1000 \mathrm{~s} / \mathrm{mm}^{2}$ in each patient. ADC maps were automatically generated for all DW images, and ADC values were measured at $b$ value $1000 \mathrm{~s} / \mathrm{mm}^{2}$. Mean ADC value measured by placing ROI of about $1 \mathrm{ccm}$ in the solid part of the lesion and expressed in $10^{-3} \mathrm{~mm}^{2} / \mathrm{s}$

\section{Histopathological correlation}

DW-MRI findings were associated with histopathologic evaluation as a gold standard for all patients. According to the histopathological findings, the lesions studied were divided into benign and malignant groups.

\section{Statistical analysis}

Statistical Package for Social Sciences, version 19, was used. Data were statistically described in terms of range, mean, standard deviation, frequencies (number of cases), and percentages when appropriate. Sensitivity, specificity, accuracy, positive predictive value, and negative predictive value for the conventional MRI and DWI were calculated separately for each parameter.

\section{Results}

A total of 50 patients were included in our study with endometrial lesions causing vaginal bleeding, about 32 patients were postmenopausal and 18 were premenopausal, 
and their age ranged from 25 to 87 years old $(M= \pm 49.6$ years) (Figs. 1, 2, 3, and 4).

\section{Histopathological results of studied lesions}

The 50 lesions included in this study were classified according to their histopathological results into two groups: group I, benign lesions (28 lesions; $56 \%$ ), and group II, malignant lesions (22 lesions; 44\%) (Table 1).

\section{Conventional MRI findings in all studied endometrial focal} lesions

Most of the studied benign and malignant endometrial focal lesions (43/50) showed low signal intensity on T1weighted images and intermediate to high signal on T2-
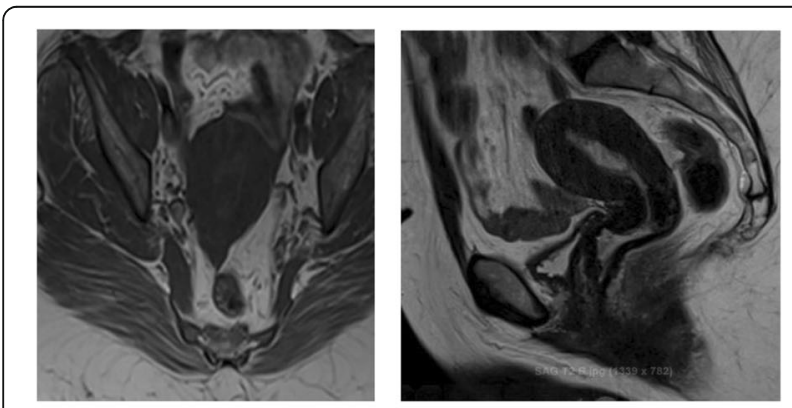

a

b

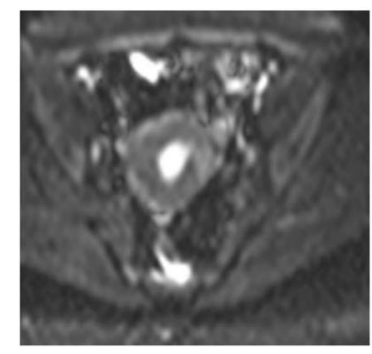

c

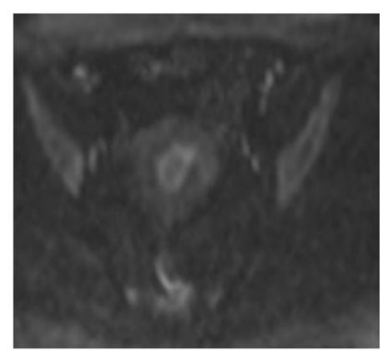

d

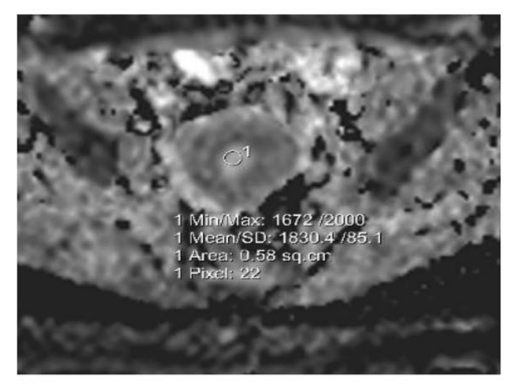

e

Fig. 1 Sagittal T2-WI (b) revealed a well-defined, small, hyperintense lesion inside the endometrium. Axial T1-WI (a) showed a

hypointense signal intensity from the lesion. Diffusion-weighted imaging at $b=0$ (c) and $b=1000$ (d) showed a low signal intensity from the lesion at high $b$ values (benign feature). ADC mapping (e) showed a high $\mathrm{SI}$ from the mass lesion with an ADC of $1.83 \times 10^{-3}$ $\mathrm{mm}^{2} / \mathrm{s}$. Radiological diagnosis: small benign featuring lesion seen inside the endometrium likely endometrial polyp. Final diagnosis (according to histopathology): endometrial polyp

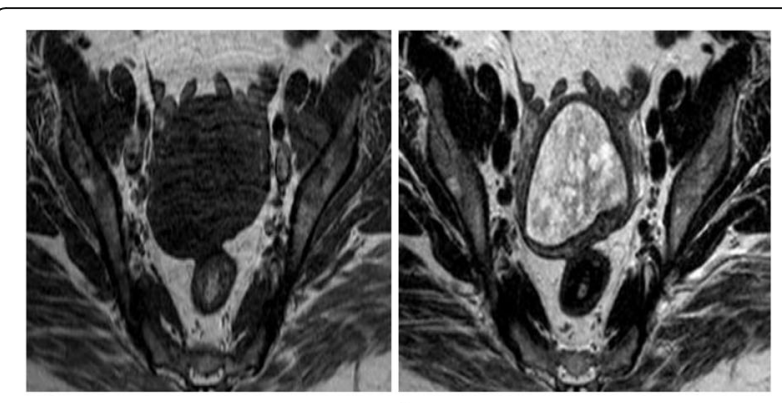

a

b
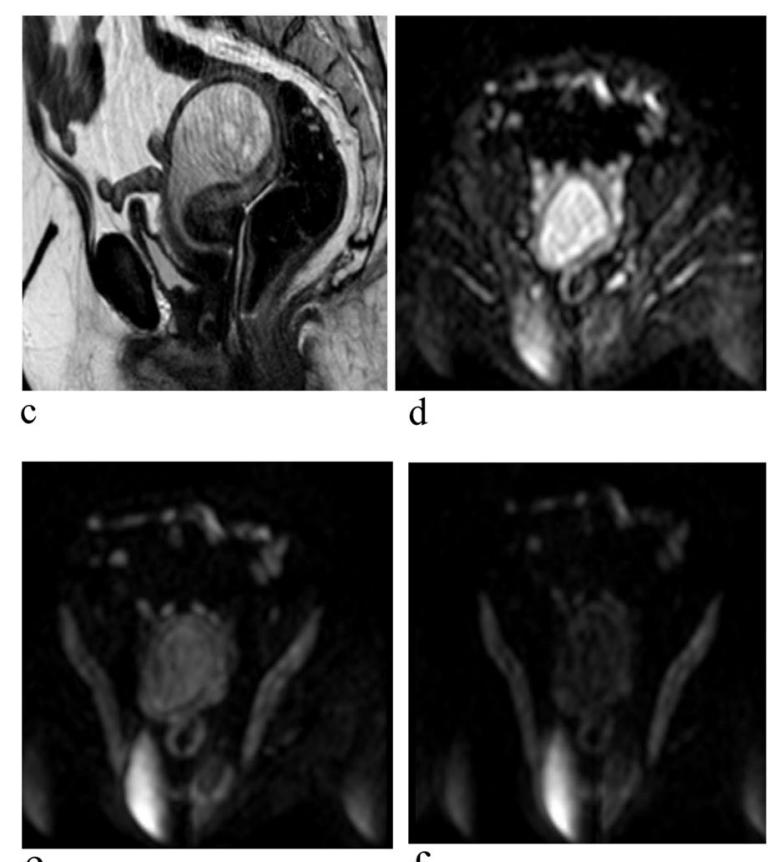

e f

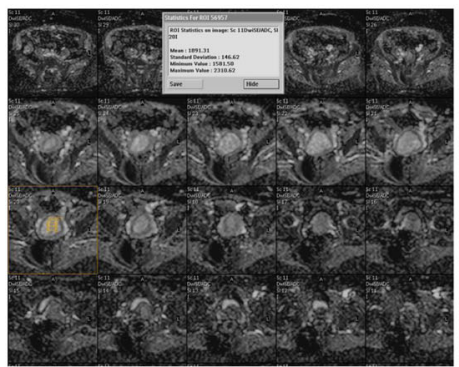

g

Fig. 2 Axial T1-WI (a) revealed a hypointense signal intensity from the thickened endometrium. Axial T2- (b) and sagittal T2-WI (c) revealed diffuse thickening of the endometrium forming a mass-like lesion with a homogenous, high $\mathrm{SI}$, and no infiltration of the junctional zone. Diffusion-weighted imaging at $b=0(\mathbf{d}), b=500$ (e), and $\mathrm{b}=1000$ (f) showed that the thickened endometrium lost its high SI with increasing $b$ values (benign feature). ADC mapping (g) showed a homogenous high SI from the thickened endometrium with an ADC of $1.891 \times 10^{-3} \mathrm{~mm}^{2} / \mathrm{s}$. Radiological diagnosis: benign featuring increased endometrial thickening forming a mass-like lesion likely endometrial hyperplasia. Final diagnosis (according to histopathology): endometrial hyperplasia 

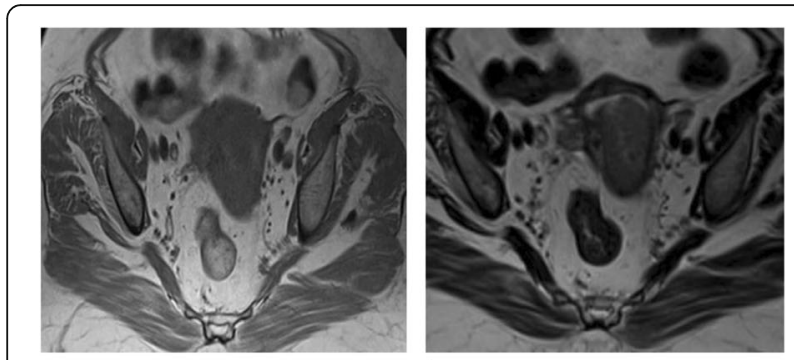

a

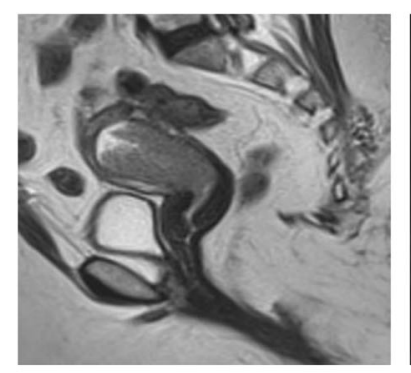

c

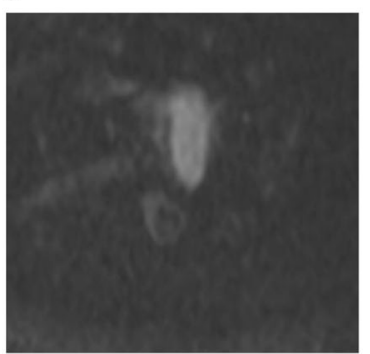

$\mathrm{e}$

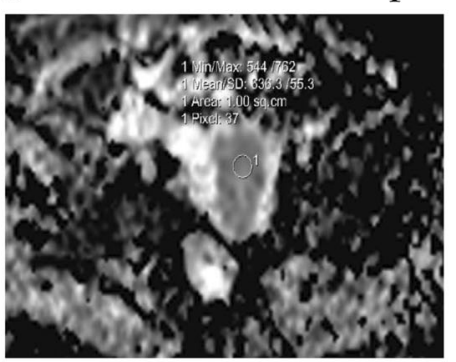

$\mathrm{g}$

Fig. 3 a Axial T1-WI revealed a slight hypointense signal intensity from the endometrial lesion. b Axial T2-WI and c Sagittal T2-WI revealed an endometrial mass lesion with a homogenous intermediate $\mathrm{SI}$ and infiltration of the junction zone affecting more than $50 \%$ of the myometrium. $\mathbf{d}$ Diffusion-weighted imaging at $b=0, \mathbf{e} b=500$, and $\mathbf{f}$ $b=1000$ showed a high signal intensity from the endometrium mass lesion at a high $b$ value (malignant feature). $\mathbf{g}$ ADC mapping showed low SI from the endometrium mass with an ADC of $0.636 \times 10^{-3} \mathrm{~mm}^{2} / \mathrm{s}$. Radiologic diagnosis: malignant featuring endometrial mass lesion likely endometrial carcinoma. Final diagnosis (according to histopathology): endometrial carcinoma

weighted images with the exception of 5 lesions that proved to be submucosal fibroid that showed low signals in both T1- and T2-WI and 2 lesions of focal adenomyosis that were seen as increased thickness of the junctional

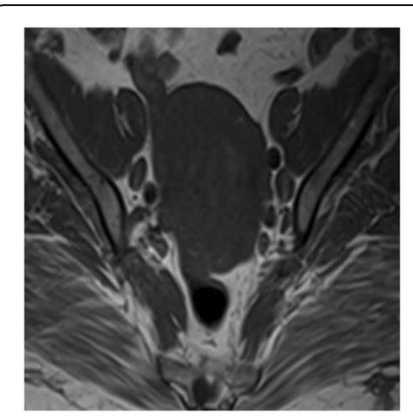

a

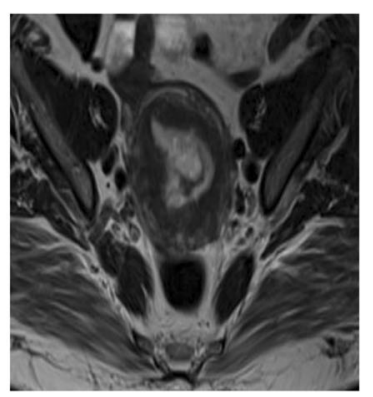

b
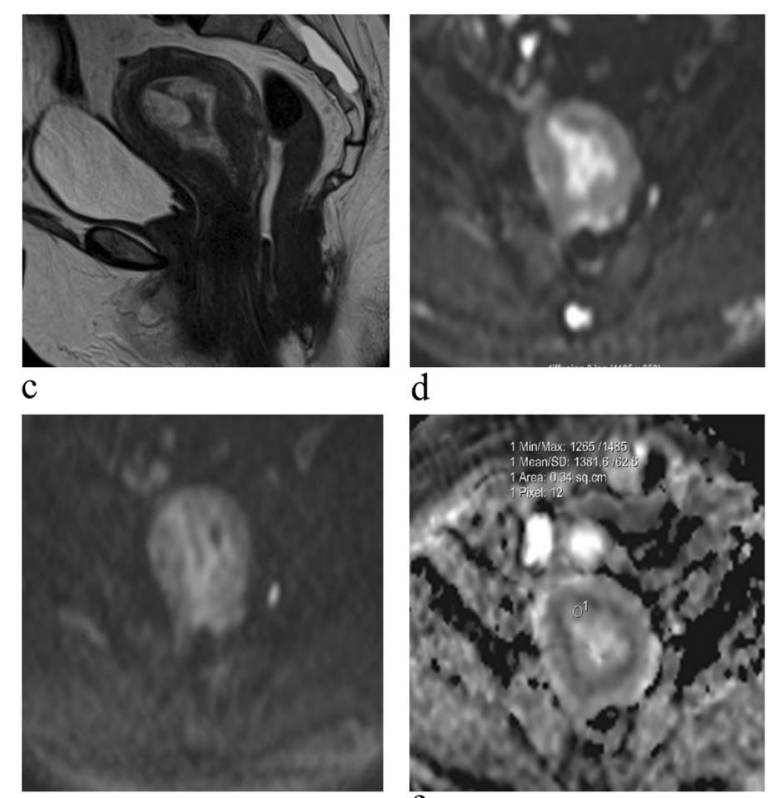

d

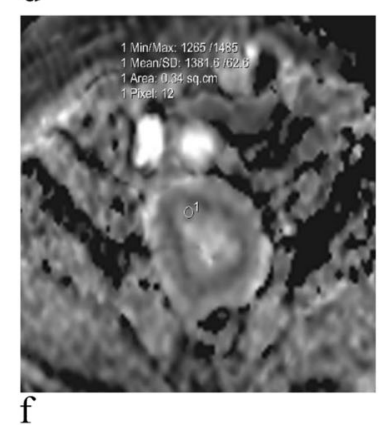

e

f

Fig. 4 a Axial T1-WI revealed slight hypointense signal intensity from the endometrial lesion. $\mathbf{b}$ Axial T2-WI and $\mathbf{c}$ sagittal T2-WI revealed an increase in endometrial thickness forming a mass lesion with a high $\mathrm{Sl}$ and inner areas of low Sl; there was infiltration of the junction zone less than $50 \%$ of the myometrium which was affected. d Diffusion-weighted imaging at $b=0$ and e $b=1000$ showed loss of the high SI of the endometrial lesion at increased $b$ values (benign feature). $\mathbf{f}$ ADC mapping showed a high SI of the endometrial mass with ADC of $1.341 \times 10^{-3} \mathrm{~mm}^{2} / \mathrm{s}$. Radiologic diagnosis: endometrial mass lesion with suspicious criteria at conventional MRI and benign features at DW and ADC images. Final diagnosis (according to histopathology): well-differentiated endometrial carcinoma

zone with ill-defined focal lesions of low signal on T1and T2-WI but with bright dots on T2-weighted images (Table 2).

\section{DWI findings with $A D C$ value measurements in group I: benign focal lesions $(n=28)$}

The majority of the studied benign uterine focal lesions $(26 / 28)$ were diffusion negative in the form of either low signals in DWI with high signals in ADC value (facilitated diffusion) or high signals in both DWI and ADC 
Table 1 Histopathological results of all studied lesions $(n=50)$

\begin{tabular}{lll}
\hline Lesions & Number & Percent \\
\hline Group I: benign lesions & 28 & 56 \\
Endometrial hyperplasia & 15 & 30 \\
Endometrial polyp & 6 & 12 \\
Submucous leiomyoma & 5 & 10 \\
Focal uterine adenomyosis & 2 & 4 \\
Group II: malignant lesions & 22 & 45 \\
Endometrial carcinoma & 17 & 34 \\
Choriocarcinoma & 5 & 10 \\
Total & 50 & 100 \\
\hline
\end{tabular}

map (T2 shin effect) with the exception of uterine fibroid that showed T2-WI blackout effect evidenced as low signal in both DWI and ADC map. The ADC value of all benign focal lesions showed relatively high values that ranged from 1.36 to $1.89 \times 10^{-3} \mathrm{~mm}^{2} / \mathrm{s}$ with mean ADC value about $1.52 \pm 0.25 \times 10^{-3} \mathrm{~mm}^{2} / \mathrm{s}$ with the exception of submucous fibroid that showed very low ADC values ranging from 0.79 to $0.86 \times 10^{-3} \mathrm{~mm}^{2} / \mathrm{s}$ with mean ADC value about $0.8 \pm 0.27$. Only two benign lesions $(2 / 28)$ showed positive diffusion changes "restricted diffusion," with low ADC values (1.19 and 1.23 $\times 10^{-3} \mathrm{~mm}^{2} / \mathrm{s}$ ), one proved to be endometrial hyperplasia while the other diagnosed as endometrial polyp according the histopathologic results (Table 3).

DWI findings with ADC value measurements in group II: malignant focal lesions $(n=22)$

Twenty lesions of the studied 22 malignant endometrial focal lesions were diffusion positive (restricted diffusion) being of high signal intensity at DWI with persistent or increased signals at high $b$ value $(b=1000)$ and low signal intensity at ADC map images while the 2 endometrial carcinomas were diffusion negative in the form of intermediate signal intensity at DWI at high $b$ value $(b=1000)$ and high signal intensity at ADC images that proved to be degenerated and of low cellularity on histopathologic correlations. The ADC value of studied malignant

Table 2 Conventional MRI findings in all studied lesions ( $n=$ 50)

\begin{tabular}{llll}
\hline Lesions & Number & T1-WI & T2-WI \\
\hline End. hyperplasia & 15 & Iso-low SI & Intermediate-high SI \\
End. polyp & 6 & Iso-low SI & Homogenous high SI \\
Submucosal fibroid & 5 & Iso-low SI & Low SI \\
Focal adenomyosis & 2 & Iso-low SI & Low SI with bright foci \\
End. carcinoma & 17 & Iso-low SI & Intermediate-high SI \\
Choriocarcinoma & 5 & Iso-low SI & Intermediate-high SI \\
Total & 50 & & \\
\hline
\end{tabular}

endometrial lesions showed relatively low values that ranged from 0.636 to $1.241 \times 10^{-3} \mathrm{~mm}^{2} / \mathrm{s}$ with mean ADC value about $0.95 \pm 0.24 \times 10^{-3} \mathrm{~mm}^{2} / \mathrm{s}$ (Table 4 ).

\section{The validity of conventional MRI/DW-MRI in the diagnosis} of all studied endometrial focal lesions

In the current study, conventional MRI could correctly diagnose 39 lesions out of the studied 50 lesions, 22/28 benign lesions and 17/22 malignant lesions, achieving $77.27 \%$ sensitivity, $78.56 \%$ specificity, $78 \%$ accuracy, $73.91 \%$ predictive positive value (PPV), and $81.48 \%$ negative positive value (NPV). When adding DWI with ADC value measurements at high $b$ value $(b=1000)$ to MRI exam, we could correctly diagnose 47 lesions out of the studied 50 lesions, 26/28 benign lesions and 21/22 malignant lesions, achieving 95.45\% sensitivity, 92.86\% specificity, 94\% accuracy, 91.3\% PPV, and 96\% NPV (Table 5).

\section{Discussion}

Recently, MRI was considered better than CT for the detection and staging of gynecological and pelvic malignancies [10].

This study included 50 endometrial focal lesions that were grouped according to histopathology into a benign group (28 lesions) and a malignant group (22 lesions). Endometrial hyperplasia was the most common benign lesion $(n=15)$ followed by endometrial polyps $(n=6)$, while endometrial carcinoma was the most common malignant lesion $(n=17)$ followed by choriocarcinoma $(n=5)$.

Our results are in agreement with those of Elsammak et al., who classified 42 lesions as benign ( 24 cases) and malignant (18 cases) groups according to their histopathology results and found that the most common benign lesion was endometrial hyperplasia, while the most common malignant lesion was endometrial carcinoma [3]. Additionally, Kilickesmez et al. reported that endometrial carcinoma was the most common malignant endometrial lesions [11]. Kececi et al. found that 40/42 of the studied malignant lesions were endometrial carcinoma, while $7 / 14$ of the studied benign lesions were endometrial polyps: 5 were submucosal fibroids and only 2 lesions were endometrial hyperplasia [12].

In the current study, conventional MRI showed relatively low diagnostic accuracy in the differentiation of different endometrial focal lesions, as most of the studied benign and malignant lesions showed an iso-low signal intensity on T1-WI and an intermediate-high signal intensity on T2-WI with the exception of five submucosal fibroids that showed low signals on both T1-WI and T2-WI and two focal adenomyosis that showed increased thickness of the junctional zone with low signal foci on T1- and T2-WI but with bright dots on T2-WI.

Our results were in a concordance with those of Kierans et al., who reported that conventional MRI features 
Table 3 DWI and ADC map findings in group I (benign lesions, $n=28$ )

\begin{tabular}{|c|c|c|c|c|}
\hline Lesion & Number & DWI $(b=1000)$ & ADC map & ADC value \\
\hline End. hyperplasia (15) & $\begin{array}{l}10 \\
4 \\
1\end{array}$ & $\begin{array}{l}\text { Low SI } \\
\text { High SI } \\
\text { High }\end{array}$ & $\begin{array}{l}\text { High SI } \\
\text { High SI } \\
\text { Intermediate }\end{array}$ & $\begin{array}{l}1.561-1.891 \\
\text { Mean }=1.726 \pm 0.25 \\
1.23\end{array}$ \\
\hline End. polyp & $\begin{array}{l}5 \\
1\end{array}$ & $\begin{array}{l}\text { Low SI } \\
\text { High }\end{array}$ & $\begin{array}{l}\text { High SI } \\
\text { Low }\end{array}$ & $\begin{array}{l}1.816-1.924 \\
\text { Mean }=1.865 \pm 0.18 \\
1.19\end{array}$ \\
\hline Submuc. fibroid & 5 & Low SI & Low SI & $\begin{array}{l}0.79-0.86 \\
\text { Mean }=0.8 \pm 0.27\end{array}$ \\
\hline Focal adenomyosis & 2 & Low SI & High SI & $\begin{array}{l}0.98-1.23 \\
\text { Mean }=1.18 \pm 0.15\end{array}$ \\
\hline
\end{tabular}

regarding morphology and signal characteristics were not significantly different in both benign and malignant endometrial pathologies [13]. Additionally, other studies have shown that endometrial polyps and benign hyperplasia often present as a focal mass occupying the uterine cavity or as nonspecific endometrial thickening, and those signs are not sufficient for accurate diagnosis of carcinoma, hyperplasia, and polyps [10]. Tamai et al. reported that ordinary leiomyomas exhibited low signals on both T1- and T2-weighted images [14].

DW-MRI is a functional imaging technique that does not require the exogenous contrast medium administration required [15]. When DWI is combined with MRI, it becomes a good diagnostic tool and provides more information for the differentiation and extension of benign and malignant lesions [16].

According to the present work results, DWI could aid in the differentiation between benign and malignant focal endometrial lesions as most of the studied benign lesions (23/28) showed negative diffusion results, and the remaining 5 submucosal fibroids showed T2-WI blackout effects. The ADC values of benign lesions were found to be relatively high when measured at high $b$ value $\left(b=1000 \mathrm{~m}^{2}\right)$, ranging from 1.36 to $1.89 \times 10^{-3}$ $\mathrm{mm}^{2} / \mathrm{s}\left(\mathrm{M}=1.52 \pm 0.25 \times 10^{-3} \mathrm{~mm}^{2} / \mathrm{s}\right)$, although they were very low for the submucosal fibroids ranging from 0.79 to $0.86 \times 10^{-3} \mathrm{~mm}^{2} / \mathrm{s}(\mathrm{M}=8 \pm 0.27)$. On the other hand, 21/22 malignant endometrial focal lesions were diffusion positive (restricted diffusion), with only 1 endometrial carcinoma that was diffusion negative. The ADC values of the malignant endometrial focal lesions were relatively low ranging from 0.636 to $1.241 \times 10^{-3} \mathrm{~mm}^{2} / \mathrm{s}$ $\left(\mathrm{M}=0.95 \pm 0.24 \times 10^{-3} \mathrm{~mm}^{2} / \mathrm{s}\right)$ when measured at high $b$ value $(b=1000)$.
These results are consistent with the results of Elsammak et al. [3], who found a significant difference between the mean ADC values of malignant masses $(0.82$ $\left.\times 10^{3} \mathrm{~mm}^{2} / \mathrm{s}\right)$ and benign lesions $\left(1.44 \times 10^{-3} \mathrm{~mm}^{2} / \mathrm{s}\right)$, and those of Kececi et al. [12], who revealed that the mean ADC value of 42 malignant lesions $(0.94 \pm 0.18 \times$ $10^{-3} \mathrm{~mm}^{2} / \mathrm{s}$ ) was statistically significantly lower than the mean ADC value of benign lesions $\left(1.45 \pm 0.22 \times 10^{-3}\right.$ $\left.\mathrm{mm}^{2} / \mathrm{s}\right)(P<0.01)$, and matched also with Fujii et al. [17], who concluded that malignant tumors namely endometrial carcinoma and carcinosarcoma show lower ADC values than benign tumors. Also, Thulaseedharan et al. [18] and Heo et al.'s [19] studies showed that there was a much lower ADC value for malignant endometrial lesions compared to the benign endometrial lesions.

Our findings as regards DWI results of Submucosal fibroids with the findings of Thomassin-Naggara et al. [20], that revealed DWI low signal intensity for all leiomyomas and as well Namimoto et al. [21] who stated that all studied ordinary leiomyomas $(n=95)$ were diffusion negative with low SI on DWI, however, Shen et al. [22] stated that submucosal myomas had different mean $\mathrm{ADC}$ values that may overlap with malignant lesions.

In our study, conventional MRI study only correctly diagnosed 39/50 studied lesions, achieving $77.27 \%$ sensitivity, $78.56 \%$ specificity, 78\% accuracy, $73.91 \%$ PPV, and 81.48\% NPV. When adding DWI with ADC value measurements at high $b$ value $(b=1000)$, we could correctly diagnose 47/50 lesions that increased diagnostic sensitivity to $95.45 \%$, specificity to $92.86 \%$, and accuracy to $94 \%$, as well as PPV to $91.3 \%$ and NPV to $96 \%$.

Our results were in harmony with Elsammak et al.'s [3] results which concealed that conventional MRI could correctly diagnose $36 / 42$ cases, achieving $77.8 \%$

Table 4 DWI and ADC map findings in group II (malignant lesions, $n=22$ )

\begin{tabular}{|c|c|c|c|c|}
\hline Lesion & Number & DWI $(b=1000)$ & ADC map & ADC value \\
\hline End. carcinoma & $\begin{array}{l}15 \\
2\end{array}$ & $\begin{array}{l}\text { High SI } \\
\text { Intermediate }\end{array}$ & $\begin{array}{l}\text { Low SI } \\
\text { High SI }\end{array}$ & $\begin{array}{l}0.636-1.21 \\
\text { Mean }=0.86 \pm 0.25\end{array}$ \\
\hline Choriocarcinoma & 5 & High SI & Low SI & $\begin{array}{l}0.79-1.19 \\
\text { Mean }=1 \pm 0.18\end{array}$ \\
\hline
\end{tabular}


Table 5 Validity of conventional MRI/DW-MRI in the diagnosis of all studied endometrial lesions $(n=50)$

\begin{tabular}{llllll}
\hline & Sensitivity & Specificity & Accuracy & PPV & PPV \\
\hline Conv. MRI & $77.27 \%$ & $78.56 \%$ & $78 \%$ & $73.91 \%$ & $81.48 \%$ \\
DW-MRI & $95.45 \%$ & $92.86 \%$ & $94 \%$ & $91.3 \%$ & $96 \%$ \\
\hline
\end{tabular}

sensitivity, 99.17\% specificity, 87.5 PPV, and 84.6\% NPV, and matched also with Bharwani et al. [23] who stated that the addition of DWI to conventional MRI has increased the sensitivity and specificity to $86 \%$ and $100 \%$, respectively, in the diagnosis of uterine endometrial lesions; Takeuchi et al. [24, 26] reported a sensitivity and specificity of DWI in endometrial lesions which were $100 \%$ and $81 \%$, respectively.

\section{Conclusion}

Adding MRI diffusion with ADC mapping at a high $b$ value in MRI examination of the pelvis is valuable for the differentiation of both benign and malignant endometrial lesions with high diagnostic sensitivity, specificity, and accuracy.

\section{Abbreviations}

ADC: Apparent diffusion coefficient; CT: Computed tomography; DWI: Diffusion-weighted imaging; FOV: Field of view; FSE: Fast spin echo; MRI: Magnetic resonance imaging; NPV: Negative positive value; PPV: Predictive positive value; TE: Time echo; TR: Time repetition; US: Ultrasound

\section{Acknowledgements}

Not applicable.

\section{Authors' contributions}

TM contributed in the data collection, image revision, and final editing. YA shared in the editing of the manuscript. GhR contributed to the revision of the manuscript. All authors have read and approved the research, and agree for the submission.

\section{Funding}

Not applicable.

\section{Availability of data and materials}

The datasets analyzed during the current study available from the corresponding author on reasonable request.

\section{Ethics approval and consent to participate}

This study was done after the approval from the AL-Azhar University Hospital, Faculty of Medicine, Assiut, and after the patients agreed with verbal consent (as the patients were not exposed to any type of surgical or intervention maneuver). This study was done during January 2018 till January 2019. The number of meeting code is 4 , and the number of paper code is 7 .

\section{Consent for publication}

All patients included in this research gave written informed consent to publish the data contained within this study. If the patient was less than 16 years old, deceased, or unconscious when consent for publication was requested, written informed consent for the publication of this data was given by their parent or legal guardian.

\section{Competing interests}

The authors declare that they have no competing interests.

\section{Author details}

'Radio-diagnosis Department, Faculty of Medicine, Al-Azhar University, Assiut, Egypt. ${ }^{2}$ Radio-diagnosis Department, Faculty of Medicine, South Valley University, Qena, Egypt.

Received: 14 June 2019 Accepted: 29 October 2019

Published online: 26 December 2019

\section{References}

1. Keriakos NN, Darwish E (2018) Diffusion-weighted imaging in suspicious uterine tumors; how efficient is it? Egypt J Radiol Nucl Med 49:838-845

2. Claudia T, Sadro MD (2016) Imaging the endometrium: a pictorial essay. Can Assoc Radiol J 67(3):254-262

3. Elsammak A, Shehata SM, Mona A et al (2017) Efficiency of diffusionweighted magnetic resonance in differentiation between benign and malignant endometrial lesions. Egypt J Radiol Nucl Med 48:751

4. Sala E, Crawford R, Senior E et al (2009) Added value of dynamic contrastenhanced magnetic resonance imaging in predicting advanced stage disease in patients with endometrial carcinoma. Int J Gynecol Cancer 19: 141-146

5. Bazot M, Darai E, Nassar-Slaba J et al (2008) Value of magnetic resonance imaging for the diagnosis of female pelvis tumors: a review. J Comput Assist Tomogr 32(5):712-723

6. Sohaib SA, Mills TD, Sahdev A et al (2005) The role of magnetic resonance imaging and ultrasound in patients with adnexal masses. Clin Radiol 60(3): 340-348

7. Whittaker C, Coady A, Culver L et al (2009) Diffusion-weighted MR imaging of female pelvic tumors: a pictorial review. Radio Graphics 29(3):759-778

8. Pagani E, Bizzi A, Di Salle F et al (2008) Basic concepts of advanced MRI techniques. NeurolSci. 29(3):290-295

9. Saremi F, Knoll AN, Bendavid OJ et al (2009) Characterization of genitourinary lesions with diffusion-weighted imaging (abstract). Radiographics 29(5):1295-1317

10. Sala E, Rockall A, Rangarajan D et al (2010) The role of dynamic contrastenhanced and diffusion-weighted magnetic resonance imaging in the female pelvis. Eur J Radiol 76(3):367-385

11. Kilickesmez O, Bayramoglu S, Inci E et al (2009) Quantitative diffusionweighted magnetic resonance imaging of normal and diseased uterine zones. Acta Radiol 50(3):340-347

12. Kececi IS, Nural MS, Aslan K et al (2016) Efficacy of diffusion-weighted magnetic resonance imaging in the diagnosis and staging of endometrial tumors. Diagn Interv Imaging 97:177-186

13. Kierans AS, Bennett GL, Haghighi M et al (2014) Utility of conventional and diffusion-weighted MRI features in distinguishing benign from malignant endometrial lesions. Eur J Radiol 83:726-732

14. Tamai K, Koyama T, Saga T et al (2008) The utility of diffusion-weighted MR imaging for differentiating uterine sarcomas from benign leiomyomas. Eur Radiol 18(4):723-730

15. Nougaret S, Tirumani SH, Addley H et al (2013) Pearls and pitfalls in MRI of gynecologic malignancy with diffusion-weighted technique. AJR Am J Roentgenol 200(2):261-276

16. Namimoto T, Awai K, Nakaura T et al (2009) Role of diffusion-weighted imaging in the diagnosis of gynecological diseases. Eur Radiol 19(3):745-760

17. Fujii S, Matsusue E, Kigawa J (2008) Diagnostic accuracy of the apparent diffusion coefficient in differentiating benign from malignant uterine endometrial cavity lesions: initial results. Eur Radiol 18:384-389

18. Thulaseedharan JV, Malila N, Hakama M, Esmy PO, Cherian M, Swaminathan R, Muwonge R, Sankaranarayanan R (2013) Effect of screening on the risk estimates of socio demographic factors on cervical cancer - a large cohort study from rural India. Asian Pac J Cancer Prev 14:589-594. https://doi.org/ 10.7314/APJCP.2013.14.1.589 PMID: 23534800

19. Heo SH, Shin SS, Kim JW, Lim HS, Jeong YY, Kang WD, Kim SM, Kang HK (2013) Pre-treatment diffusion-weighted MR imaging for predicting tumor recurrence in uterine cervical cancer treated with concurrent chemoradiation: value of histogram analysis of apparent diffusion coefficients. Korean J Radiol 14:616-625. https://doi.org/10.3348/kjr.2013.14. 4.616 PMID: 23901319

20. Thomassin-Naggara I, Dechoux S, Bonneau C et al (2013) How to differentiate benign from malignant myometrial tumors using MR imaging. Eur Radiol 23(8):2306-2314 
21. Namimoto T, Yamashita Y, Awai K et al (2009) Combined use of T2weighted and diffusion-weighted 3-T MRI for differentiating uterine sarcomas from benign leiomyomas. Eur Radiol 19:2756-2764

22. Shen SH, Chiou YY, Wang JH et al (2008) Diffusion-weighted single-shot echo-planar imaging with parallel technique in the assessment of endometrial cancer. AJR Am J Roentgenol 190:481-488

23. Lee SI, Catalano OA, Dehdashti F (2015) Evaluation of gynecologic cancer with MR imaging, 18F-FDG PET/CT, and PET/MR imaging. J Nucl Med 56: 436-443. https://doi.org/10.2967/jnumed.114.145011 PMID: 25635136

24. Takeuchi M, Matsuzaki K, Nishitani H (2009) Diffusion weighted magnetic resonance imaging of endometrial cancer: differentiation from benign endometrial lesions and preoperative assessment of myometrial invasion. Acta Radiol 50:947-953

25. Wolfman DJ, Ascher SM (2006) Magnetic resonance imaging of benign uterine pathology. Top Magn Reson Imaging 17(6):399-407

26. Lane BF, Wong-You-Cheong JJ (2009) Imaging of endometrial pathology. Clin Obstet Gynecol 52(1):57-72

\section{Publisher's Note}

Springer Nature remains neutral with regard to jurisdictional claims in published maps and institutional affiliations.

\section{Submit your manuscript to a SpringerOpen ${ }^{\circ}$ journal and benefit from:}

- Convenient online submission

- Rigorous peer review

- Open access: articles freely available online

High visibility within the field

Retaining the copyright to your article

Submit your next manuscript at $\boldsymbol{\nabla}$ springeropen.com 